\title{
Fungal parasitism of the diatom Asterionella formosa Hassall (Bacillariophyceae) by Chytridiomycota
}

\author{
C. Bertrand ${ }^{1 *}$, A. Couté 2 , A. Cazaubon ${ }^{1}$ \\ ${ }^{1}$ UMR CNRS 6116 - IMEP, Laboratoire d'Ecologie des Eaux Continentales Méditerranéennes, Université Aix-Marseille III, case C31, 13397 \\ MARSEILLE cedex 20, France \\ 2 Muséum National d'Histoire Naturelle, USM 505, 12, rue Buffon, 75231 Paris cedex 05, France
}

\begin{abstract}
Many freshwater algae are parasitized by aquatic fungi belonging to the Chytridiales Order. The top-down effects of parasitism result in individual losses within algal populations. We present data on the parasitism of the diatom Asterionella formosa Hassall by chytrids, occurring in response to hydrodynamic disturbances and the architecture of the algal host on the landscape scale. Among a series of nine reservoirs, the observed pattern of parasitism depends on the levels of hydrodynamic disturbance: the rate of parasitism is higher at intermediate disturbance levels. A. formosa cells are not randomly parasitized. Whatever the disturbance levels, fungi were found to mostly parasitize cell clusters forming non-stellate colonies.
\end{abstract}

Keywords : freshwater diatom, chytrids, hydrodynamic disturbance, landscape, parasitism.

\section{Introduction}

The population dynamics of the algae growing in lacustrine ecosystems are governed by complex interactions between several environmental factors. The size of the algal populations in a natural community is determined by the in situ growth rate and the individual losses within the population. Algal responses have been mainly analysed so far in terms of the physical and chemical variability of the freshwater environment. Physical and chemical conditions certainly constitute the main factors controlling the growth rate of each algal cell under field conditions (Parsons et al. 1984, Reynolds 1989). Since the middle 70's, when some attention began to be paid to biotic interactions in phytoplanktonic studies, predation and parasitism have been known to be also reponsible for cell losses in natural populations (Takahashi 1980, Reynolds 1984, Lehman \& Sandgren 1985). A large number of algal species is infected with Chytridiomycota parasites (Paterson 1960, Canter-Lund \& Lund 1995). The-

\footnotetext{
* Corresponding author : E-mail : celine.bertrand@univ.u-3mrs.fr
}

se fungal ectoparasites grow at the surface of living algal cells and feed on the cytoplasm of their hosts (Canter \& Jaworski 1979). The fact that chytrids show a high degree of specificity for their cell host may reduce the number of algal species parasitized in a given ecosystem (Van Donk 1989). Fungal infestations of algae can reach epidemic proportions, destroying much of, and sometimes most of the algal host population. These fungi have a high growth rate that can exceed the algal population growth rate (Lund 1957). This top-down effect due to fungal parasitism can strongly affect the size of algal host populations, and favors the development of other algal species. Fungal epidemics depend in the first place on the cell density and the growth rate of the algal hosts (Bruning 1991, Holfeld 2000). Host/parasite associations are also linked to the abiotic variability of environmental conditions such as the temperature, light and nutrient concentrations, in particular (Van Donk \& Ringelberg 1983, Kudoh \& Takahashi 1990). At very low temperatures $\left(\leq 3^{\circ} \mathrm{C}\right)$, the parasitic activity of chytrids is inhibited (Van Donk \& Ringelberg 1983): the fungi form resting spores, whereas higher temperatures favor fungal growth (Van Donk 1989, Kudoh \& Takahashi 1990). Fungal parasi- 
tism may be inhibited not only directly but also indirectly at very low temperatures (Van Donk 1989): low temperatures can induce structural changes in the diatom wall and/or membrane that make algal cells more vulnerable to chytrid parasitism. In addition, the infection process by chytrids requires light (Canter \& Jaworski 1981). Movements of the chytrid zoospores are directed towards the most suitable hosts in the light, due to the presence of a chemical stimulus: exudates relaesed by the algae during the process of photosynthesis (Reynolds 1984). In the dark, the rates of adhesion to host cells are low because parasites cannot find their hosts by using chimiotactic cues (Van Donk 1989). Light limitation of the host results in unfavourable conditions for fungal parasitism (Bruning 1991). Lastly, chytrids seem to grow better on healthy cells than on nutrient-limited algae: a larger number of zoospores are produced at a faster rate on heathly cells (Van Donk 1989). However, nutrient limitation can facilitate the development of a fungal epidemic because parasite's reproductive rate will be less heavily affected by a limitation of this kind than that of the host (Bruning \& Ringelberg 1987). Chytrids frequently parasitize the diatom Asterionella formosa Hassall in temperate lakes. The parasitical epidemics occurring in A. formosa populations are linked to the algal cell density and abiotic factors such as light, temperature, and the phosphorus supply (Bruning \& Ringelberg 1987, Bruning 1991, Canter-Lund \& Lund 1995). This diatom is common in southeastern France, particularly in reservoirs (Bertrand et al. 2003a). The reservoirs in this region all have quite different morphometric and hydrodynamic characteristics due to the hydraulic regulation of the rivers. Here, the effects of human-induced hydrodynamic disturbances on the parasitism of the freshwater diatom A. formosa by chytrid fungi were studied on the landscape scale for the first time. The landscape has been defined on any scale as a mosaic of homogeneous units connected in space by exchanges of matter, energy and information (Zonneveld 1989); here each reservoir was taken to constitute one unit in the landscape studied. It was proposed to determine in addition whether the architecture of the host cell, as well as the cell density, may affect parasitism by chytrids at the landscape scale.

\section{Material and methods}

\section{Study area}

This study was carried out at the landscape scale, on a series of reservoirs located in two regulated rivers, the Durance River and its main tributary, the Verdon
(Fig. 1). The Durance-Verdon complex is located in south-eastern France, in the Mediterranean region. Due to the hydraulic regulation effected on these two rivers, the morphometric, geographical and hydrodynamic characteristics vary considerably from one reservoir to another in this complex. The present study was carried out at 9 of these reservoirs in the DuranceVerdon complex. Seven of them are hydroelectric reservoirs, three located on the Durance River (S1, S2, S3) and four on the Verdon River (S4, S5, S6, S7), owned by Electricité de France (E.D.F.). The other two reservoirs are managed by water supply companies for urban use: S8 is mainly crossed by the waters of the Durance River, and S9 is fed by the Verdon River. There is a calcareous geological substrate at all these reservoirs.

\section{Hydrodynamic disturbance}

The hydrodynamic conditions (the frequency and intensity of mixing) in the Durance-Verdon complex are highly variable in terms of both space and time. In lacustrine ecosystems, the mixing variability is known to exert variable levels of hydrodynamic disturbance on the phytoplankton (Reynolds 1984). Disturbances can be described as any discrete events which disorganize the structure of an ecosystem, community or population and affect the food supplies, substrate availability or physical environment (White \& Pickett 1985). In this study, the hydrodynamic conditions were assessed in terms of the mean annual retention time at each reservoir; the lower the retention time, the greater are the flow in the reservoir, the mixing and the level of disturbance will be. Three levels of disturbance were defined in this complex as regards the physiological and ecological requirements of the phytoplankton (Tilman et al. 1982, Sommer 1985, Reynolds 1988). Short (from a few hours to a few days), medium (over one week) and long (over one month) retention times were taken to correspond to a high, intermediate and low level of hydrodynamic disturbance, respectively.

In order to classify the nine reservoirs in terms of their morphometric features and the mode of hydraulic management used in these lentic habitats, a correspondence analysis was conducted on a set of qualitative data (Hill \& Smith 1976) including altitude, mean depth, storage capacity, area, mean retention time, maximum water level variations, mixing rate, and year of completion of the reservoir. The values of these variables are expressed in line with the categories defined in the ADE-4 software program (Thioulouse et al. 1997) on the basis of the phytoplankton requirements (Table 1). 


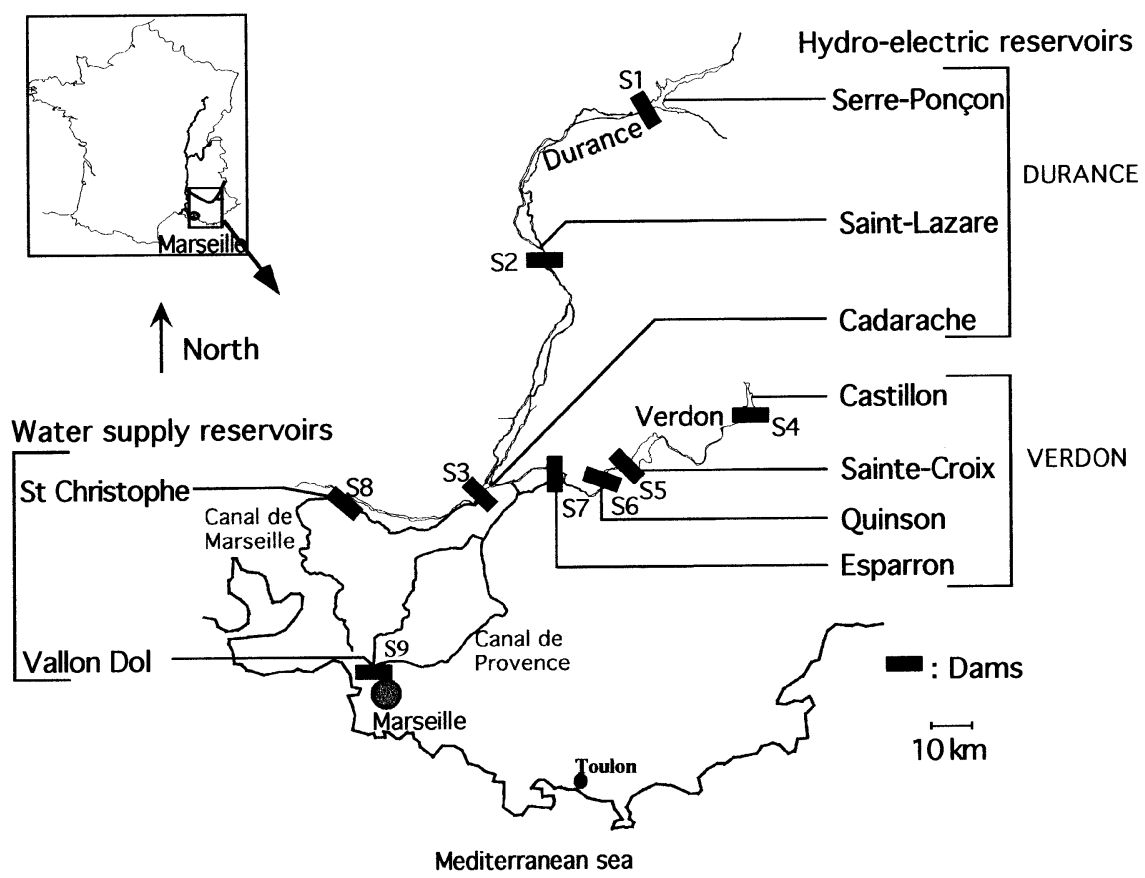

Fig. 1. Location of the reservoirs studied in the Durance-Verdon complex (Southeastern France).

Table 1. Categories of various variables from the correspondence analysis realized with physical characteristics (20 categories) of 9 reservoirs of Durance-Verdon complex.

\begin{tabular}{llll}
\hline \multicolumn{4}{l}{ Categories } \\
\hline Variables & $\mathbf{1}$ & $\mathbf{2}$ & $\mathbf{3}$ \\
\hline Mean depth $(\mathrm{m})$ & $<10$ & $10-20$ & $\geq 50$ \\
Altitude $(\mathrm{m})$ & $<400$ & $>400$ & - \\
Storage capacity $\left(\mathrm{x} 10^{6} \mathrm{~m}^{3}\right)$ & $<15$ & $15-150$ & $>150$ \\
Area (ha) & $100-300$ & $300-500$ & $>2000$ \\
Mean annual retention time & $<$ week & $>$ week & $>$ month \\
Maximum level variations $(\mathrm{m})$ & $<10$ & $>10$ & - \\
Year of completion & before 1960 & after 1960 & - \\
Mixing rate & holomictic & monomictic & - \\
\hline
\end{tabular}

\section{Sampling design}

The nine reservoirs were monitored from January 1999 to June 2000. A total number of 207 phytoplankton samples $(23$ samples $x 9$ reservoirs $=207$ samples studied) were collected. At each reservoir, a sample of water was collected on each date, directly behind the dam wall, from the surface water layer (depth: $50 \mathrm{~cm}$ ) in a bottle of the Van Dorn type. Phytoplankton samples were fixed in situ in $5 \%$ neutral formalin. On each date, a sub-sample $(25 \mathrm{~mL})$ from each reservoir was examined under an inverted Olympus microscope in order to determine the cell density, the architecture 
and the rate of parasitism on A. formosa. The population of this diatom was characterized by two descriptors: the cell density (cell $\mathrm{L}^{-1}$ ) and the architecture of each algal cell. The description of the architecture of the algal cells was based on two criteria: (1) the presence of unicellular or colonial forms, and (2) the configuration of the colony: stellate or non-stellate. The non-stellate configuration occurs in a colony where two cells are not attached to each other up to the basal pole. The density of the $A$. formosa cells parasitized by chytrids was measured in each phytoplankton sample.

\section{Results}

\section{Hydrodynamic conditions in the reservoirs}

The F1xF2 factorial diagram of the correspondence analysis accounted for $75 \%$ of the total variability. The correspondence analysis of the morphometric, geographic, hydrodynamic and management characteristics showed the existence of three distinct groups of reservoirs (Fig. 2). Group 1, which was negatively correlated with axis $\mathrm{F} 1$, contains deep reservoirs $\mathrm{S} 1$, S4 and S5. These reservoirs have a large storage capacity $\left(>150 \mathrm{~m}^{3} \times 10^{6}\right)$, large level variations, reaching 50 meters at reservoir $\mathrm{S} 1$, and a water retention time of more than 100 days. These reservoirs are therefore characterized by a low level of hydrodynamic disturbance. Group 2 was negatively correlated with axis F2: it contains shallow reservoirs S7 and S9, which have intermediate storage capacities $(\leq 100$ $\mathrm{m}^{3} \times 10^{6}$ ) and retention times (one month). There are intermediate levels of hydrodynamic disturbance at these reservoirs. Group 3 was opposed to group 1 along axis F1. The very shallow reservoirs S2, S3, S6 and $\mathrm{S} 8$ in group 3 are distinguished by a very low sto-

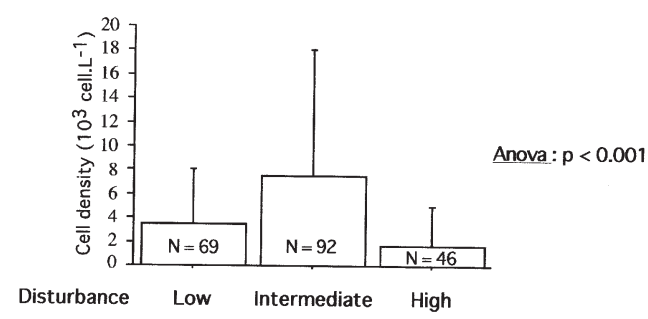

Fig. 3. Means and standard deviations (SD) of the cell densities of Asterionella formosa (cell.L-1) calculated at each group of reservoirs on 23 sampling dates. The group effect was tested with an analysis of variance (Anova: $* * * p<0.001$ : highly significant differences). rage capacity and an extremely short and variable water retention time (ranging from several hours to several days), since the retention time depends directly on the weather conditions and on the water and energy requirements. These reservoirs are also characterized by high levels of hydrodynamic disturbance. This correspondence analysis showed the great spatial heterogeneity of the hydrodynamic disturbances to which the algae at the Durance-Verdon complex are subjected: the level of hydrodynamic disturbance at the group 1, 2 and 3 reservoirs is low, intermediate and high, respectively.

\section{Spatial heterogeneity of the diatom $A$. formosa}

The densities of $A$. formosa differed significantly among the three groups of reservoirs subjected to different levels of hydrodynamic disturbance (Fig. 3). The highest cell densities were observed at intermediate disturbance levels; the densities are mostly lower at high levels of disturbance.

\section{Parasitism of Asterionella formosa}

Based on our cell counts, the number of parasitized cells of $A$. formosa was found to be highly variable among the nine reservoirs (Fig. 4). The rate of parasitism varied depending on the levels of hydrodynamic disturbance: at intermediate disturbance levels, the population of this bacillariophyceae showed greater parasitism, while at high or low disturbance levels, the parasitism was less extensive. On all the parasitized cells, the 2 to $3 \mu \mathrm{m}$-length zoospores of Chytridiale were attached to the surface of the A. formosa wall (Fig. 5), but the pattern of fungal parasitism of A. formosa depends on the architecture of the diatom. A. formosa cells forming colonies are more severely infected by Chytridiales than the unicellular forms, whatever the level of hydrodynamic disturbance in-

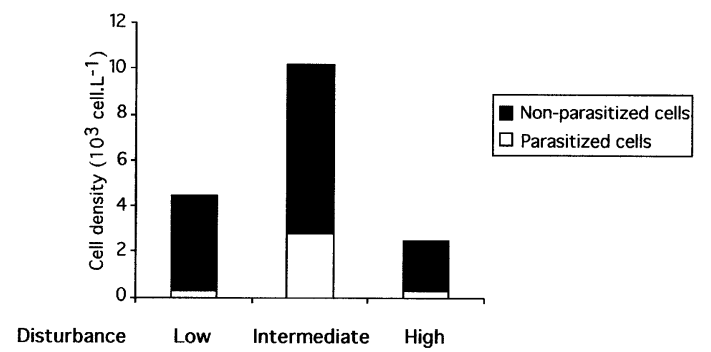

Fig. 4. Mean densities (cell.L-1) of cells of Asterionella formosa algal population parasitized by Chytridiales calculated at each group of reservoirs on all the sampling dates where A. formosa was observed. 
$\mathbf{a}$
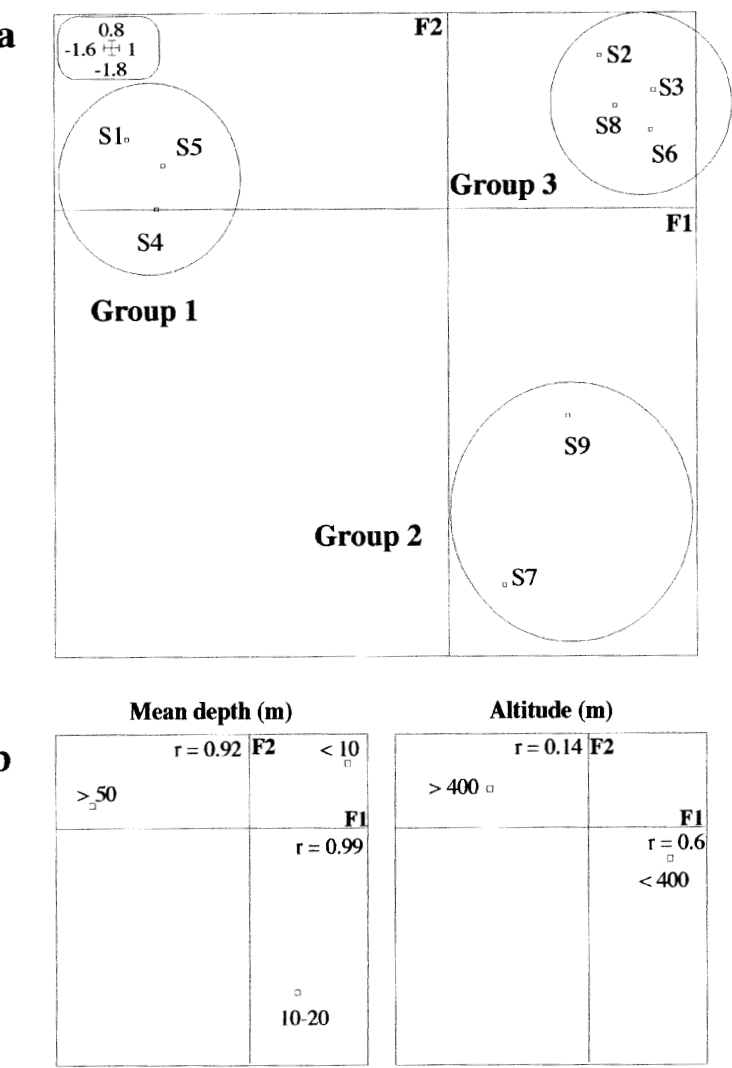

Storage capacity $\left(\mathrm{m}^{3} \times 10^{6}\right)$

Area (ha)

Mean retention time
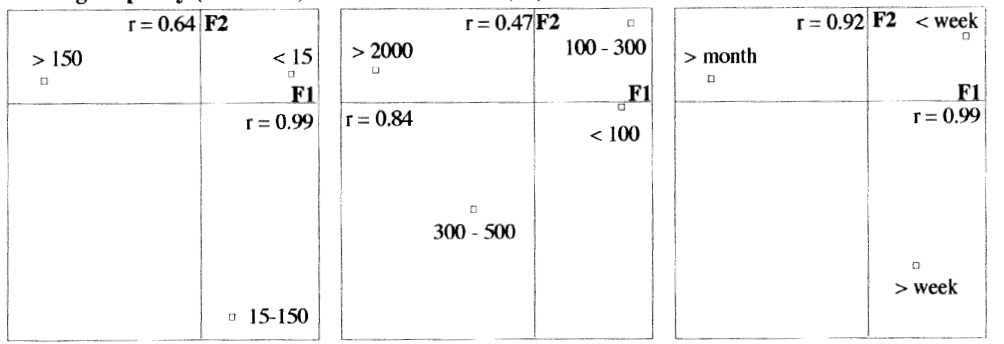

Maximal level variations (m)

Year of completion

Mixing rate
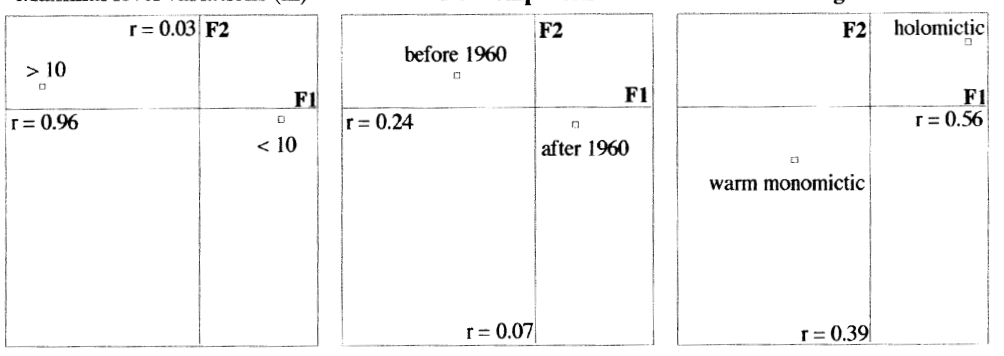

Fig. 2. Reservoirs ranked on the basis of morphometric, geographical and hydrodynamic parameters using a correspondence analysis: (a) F1x F2 factorial map of the reservoirs; (b) F1x F2 factorial map of the various physical parameters. 

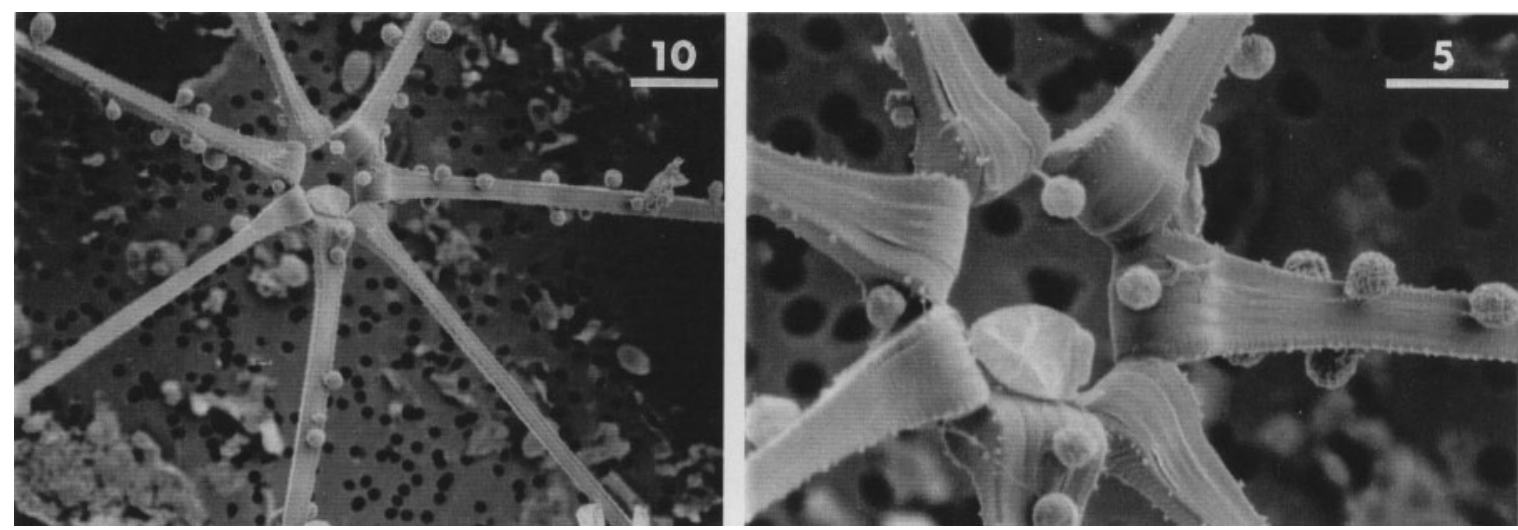

Fig. 5. Chytridiales cells attached to the surface of the diatom wall of Asterionella formosa. Scanning Electron Microscopy. Scale bar: $1 \mu \mathrm{m}$.

volved (Fig. 6a). Among the colonial forms, Chytridiales are more frequently observed at the surface of $A$. formosa cells forming non-stellate colonies (Fig. 6b).

\section{Discussion}

The correspondence analysis carried out in the present study on the morphometric, geographic, hydrodynamic and management characteristics showed the existence of three distinct groups of reservoirs in the Durance-Verdon complex: groups 1, 2 and 3 are characterized by low, intermediate and high levels of hydrodynamic disturbance, respectively, as regards the phytoplankton requirements. At the scale of the landscape formed by the Durance-Verdon complex, a gradient of $A$. formosa density occurs in response to the levels of hydrodynamic disturbance, since these levels control the ability of the diatom population to grow. Hydrodynamic disturbances are therefore likely to affect the density of the host cells liable to be potentially parasitized in lacustrine ecosystems.

The fungal parasitism carried out on A. formosa depends on the levels of hydrodynamic disturbance. Intermediate disturbance levels favor the chytrids, not only because they are associated with higher cell host densities, but also because of the morphological and physiological characteristics of the zoospores: high levels of disturbance were found to constrain the parasites and their algal host. These hydrodynamic conditions reduce the number of host cells. They are also likely to affect the swimming ability of the uniflagellated and small-sized (less than $4 \mu \mathrm{m}$ long) zoospores and their ability to efficiently detect the algal host. Low levels of hydrodynamic disturbance do not seem to be a limiting factor for chytrids; in these reservoirs,
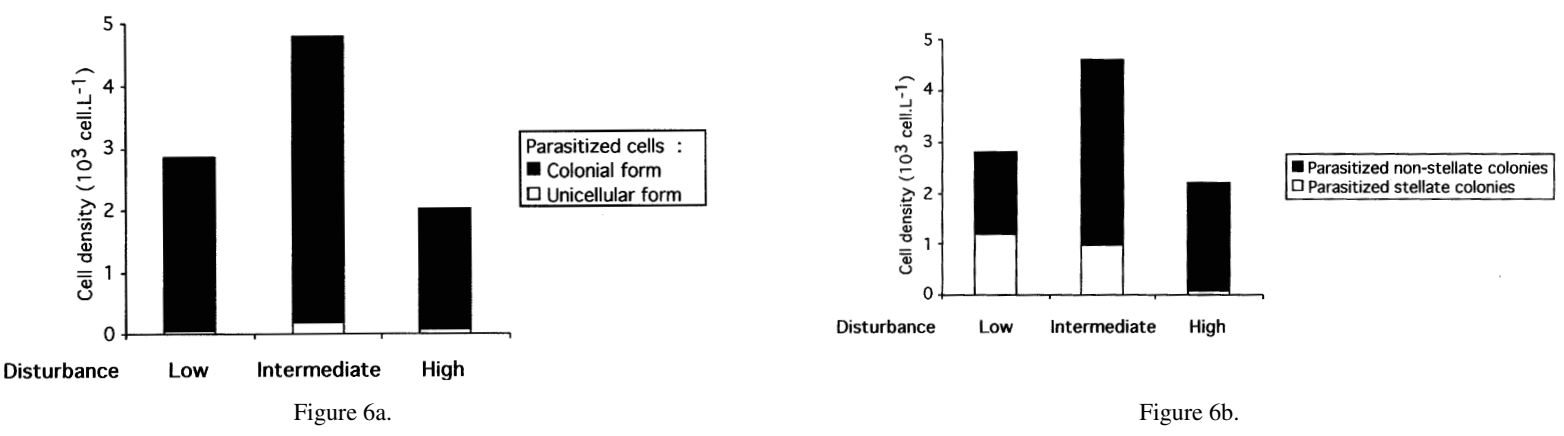

Fig. 6. Mean densities (cell.L-1) of algal cells parasitized by chytrids, depending on the architecture of Asterionella formosa, at each group of reservoirs on all the sampling dates when fungi were observed. (a) unicellular and colonial forms. (b) configuration of the colony : stellate or non-stellate. 
the temperature pattern could have an inhibitory effect on the parasites growth (Bertrand et al. 2003b). Furthermore, chytrids seem to be sensitive to the architecture of the algal hosts. The cells of A. formosa population are not randomly parasitized by fungi. Some architectural types seem to be more highly exposed to parasitism than others: the fungi were mainly found at the surface of the A. formosa cells forming non-stellate colonies. Colonies offer a larger available area for the zoospores of chytrids than the unicellular forms (Holfeld 2000). In addition, A. formosa cells release substances that attract these zoospores (Van Donk 1989, Bruning 1991). A decrease in the attractive substances released by the host will contribute to reducing the rate of infectivity (Bruning 1991). A colony consisting of a cluster of several algal cells may produce a larger quantity of substances than a single algal cell and, may thus enhance the chimiotactic processes which favor the development of chytrids.

At the landscape scale, the fungal infection of the diatom Asterionella formosa is under the control of two factors: an abiotic and allogenic factor, namely the level of hydrodynamic disturbance, and a biotic factor, namely the architecture of the algae. The processes involved in the parasitism of algae by Chytridiales are complex. In future studies, it seems to be essential to take the top-down effects of parasitism into account in order to be able to better understand the population dynamics of algae and thus, the direction of phytoplankton successions.

\section{Acknowledgements}

We are particularly grateful to numerous friends for their assistance in the field and to Dr Jessica Blanc for revising the English manuscript. This study was supported by a fellowship from Société des Eaux de Marseille (S.E.M.).

\section{References}

Bertrand C., Franquet E., Fayolle S. \& Cazaubon A. 2003a. — Une nouvelle approche de la biodiversité : plasticité morphologique chez une diatomée d'eau douce. C. R. Biologies, 326, 107-120.

Bertrand C., Fayolle S., Franquet E. \& Cazaubon A. 2003b. - Responses of the planktonic diatom, Asterionella formosa Hassall, to environnemental factors in a reservoir complex (south-eastern France). Hydrobiologia, 501, 45-58.

Bruning K. 1991. - Infection of the diatom Asterionella by a chytrid. II. Effects of light on survival and epidemic development of the parasite. J. Plankton Res., 13, 119-129.

Bruning K. \& Ringelberg J. 1987. — The influence of phosphorus limitation of the diatom Asterionella formosa on the zoospore production of its fungal parasite Rhizophydium planktonicum. Hydrobiol. Bull., 21, 49-54.

Canter H.M. \& Jaworski G.H.M. 1979. - The occurrence of a hypersensitive relation in the planktonic diatom Asterionella formo- sa Hassall parasitized by the Chytrid Rhizophydium planktonicum Canter emend., in culture. New Phytol., 82, 187-202.

Canter H.M. \& Jaworski G.H.M. 1981. - The effect of light and darkness upon infection of Asterionella formosa Hass. by the chytrid Rhizophydium planktonicum Canter emend. Ann. Bot., 47, 13-30.

Canter-Lund H. \& Lund J.W.G. 1995. - Freshwater Algae. Their microscopic world explored. Biopress, Bristol, $360 \mathrm{p}$.

Hill M.O. \& Smith A.J.E. 1976. — Principal component analysis of taxonomic data with multi-state discrete characters. Taxon, 25 , 249-255.

Holfeld H. 2000. - Relative abundance, rate of increase, and fungal infections of freshwater phytoplankton. J. Plankton Res., 22, 987-995.

Kudoh S. \& Takahashi M. 1990. - Fungal control of population changes of the planktonic diatom Asterionella formosa in a shallow eutrophic lake. J. Phycol., 26, 239-244.

Lehman J.T. \& Sandgren C.D. 1985. - Species-specific rates of growth and grazing loss among freshwater algae. Limnol. Oceanogr., 30, 34-46.

Lund J.W.G. 1957. - Fungal diseases of plankton algae. Pages 19-23 in Biological Aspects of the Transmission of Disease. Horton-Smith C. (ed). Oliver \& Bloyd, London.

Parsons T.R., Takahashi M. \& Hargrave B. 1984. — The primary formation of particulate materials. Pages 61-118 in Biological Oceanographic Processes. Pergamon.

Paterson R.A. 1960. — Infestation of chytridiceous fungi on phytoplankton in relation to certain environmental factors. Ecology, 41 416-424.

Reynolds C.S. 1984. - The ecology of freshwater phytoplankton. Cambridge University Press, Cambridge, 384 p.

Reynolds C.S. 1988. - The concept of ecological succession applied to seasonal periodicity of freshwater phytoplankton. Verh. Intern. Verein. Limnol., 23, 683-691.

Reynolds C.S. 1989. - Physical determination of phytoplankton succession. Pages 9-56 in Plankton Ecology: succession in plankton communities. Springer-Verlag, Berlin.

Sommer U. 1985. - Comparisons between steady state and nonsteady state competition: experiments with natural phytoplankton. Limnol. Oceanogr., 30, 335-346.

Takahashi M. 1980. — Controlling factors on the population dynamics of phytoplankton. Bull. Plankton Soc. Japan, 27, 139-141.

Thioulouse J., Chessel D., Dolédec S. \& Olivier J.M. 1997. - ADE$4:$ a multivariate analysis and graphical display software. Statistics and Computing, 7, 75-83.

Tilman D., Kilham S.S. \& Kilham P. 1982. — Phytoplankton community ecology: the role of limiting nutrients. Annu. Rev. Ecol. Syst., 13, 349-373.

Van Donk E. 1989. — The role of fungal parasites in phytoplankton succession. Pages 171-194 in Plankton Ecology: succession in plankton communities. Springer Verlag, Berlin.

Van Donk E. \& Ringelberg J. 1983. - The effect of fungal parasitism on the succession of diatoms in lake Maarsseveen (The Netherlands). Freshwat. Biol., 13, 241-251.

White P.S. \& Pickett S.T.A. 1985. - Natural disturbance and patch dynamics: an introduction. Pages 3-13 in The ecology of natural disturbances and patch dynamics. White P.S. \& Pickett S.T.A. (eds). Academic Press, New York.

Zonneveld I.S. 1989. - The land unit. A fundamental concept in landscape ecology, and its applications. Landsc. Ecol., 3, 67-86. 